\title{
Parents' Awareness of and Perspectives on Childhood Refractive Error and Spectacle Wear in Saudi Arabia
}

"Saif H. Alrasheed ${ }^{1,2}$ and Waleed M. Alghamdi ${ }^{1}$

\begin{abstract}
Objectives: This study aimed to assess parents' awareness of and perspectives on childhood refractive errors in Saudi Arabia. Methods: This cross-sectional study was conducted between October and November 2020 in public schools across different regions of Saudi Arabia. Data were collected using an online questionnaire that assessed parents' knowledge and perceptions of childhood refractive errors and spectacle wear. Results: A total of 358 parents from different regions of Saudi Arabia completed the questionnaire and were obtained in this study (response rate: 85\%). Approximately one third (38.3\%) of the parents reported that they had never heard of refractive errors and onethird (33.8\%) mentioned that uncorrected refractive errors did not lead to visual impairment. The majority (74.0\%) cited using eyeglasses as an effective way to manage childhood refractive errors. Two-thirds $(63.7 \%)$ stated that they did not receive any information about paediatric eye care. Better knowledge was associated with a higher educational level, female gender and older age $(P<0.001, P=0.008$ and $P=0.024$, respectively). Regarding parents' perspective on spectacle wear, $13.7 \%$ felt that using eyeglasses affected their children's chances of learning. However, $82.7 \%$ supposed that eyeglasses did not affect their children's employment opportunities. Almost a quarter of the sample (22.1\%) thought that using eyeglasses would decrease the eye's power, resulting in childhood visual impairment. Conclusion: The level of awareness and perceptions regarding childhood refractive errors and spectacle wear was low among parents. Therefore, a policy is needed to improve the awareness and perception of the key stakeholders in this issue, including parents and teachers.
\end{abstract}

Keywords: Visual Impairment; Spectacles; Parents; Attitudes; Refractive Error; Myopia; Psychological Effect; Vision Care; Eyeglasses.

\section{Advances in KNOWLedge}

The level of awareness and perceptions regarding childhood refractive errors and spectacle wear was low among parents.

\section{Application to Patient Care}

A policy is needed to improve the community's knowledge of childhood eye care, including the importance of early diagnosis and treatment of childhood eye disorders and relevant information should be delivered through public media, radio, television, social media and newspapers.

Parents' awareness of childhood refractive errors and related complaints may lead them to pursue early eye care for their children, which could result in prompt diagnosis and treatment of eye disorders and help decrease the causes of avoidable childhood blindness.

Eye care professionals should help advance parental knowledge of childhood eye care.

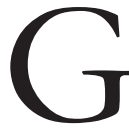

LObal estimates indicate that THERE are approximately 19 million visually impaired children worldwide. Of these children, 1.4 million are blind and 17.5 million have reduced vision; most of these cases are found in poor countries. ${ }^{1-3}$ Visual disability due to uncorrected refractive errors (REs) affects nearly 250 million individuals globally and studies have revealed that uncorrected REs are the leading cause of visual impairment. $^{4-7}$ The World Health Organization (WHO) has also reported that uncorrected REs are the leading cause of childhood visual impairment worldwide and it estimated that approximately $80 \%$ of reduced vision could be prevented by early diagnosis and management. ${ }^{1,5,8}$ There are several types of REs (ametropia), the most common being hyperopia, myopia and astigmatism. Ametropia is more prevalent among Asians and Europeans and less common among African children. ${ }^{3-7}$

Studies have shown that REs, particularly myopia, affect more than one-third of the population globally. ${ }^{4,9,10}$ While the exact cause of REs is still unknown, the common risk factors include inheritance, nutrition, indoor activities, near-vision tasks and the environment. Uncorrected REs have a significant effect on children and could limit their chances in relation to education, quality of life and efficiency, ${ }^{3,11}$ Earlier studies have reported that visual impairment is low in childhood compared to adulthood and it has a significant negative impact on the lifespan of children, 
with an estimated $60 \%$ of children dying within one year of becoming blind. ${ }^{11,12} \mathrm{Al}$ Wadaani et al. reported that the prevalence of childhood REs in Al Hassa, Saudi Arabia was $13.7 \% .^{13}$ However, another study by Aldebasi in the Qassim region of Saudi Arabia revealed the prevalence of childhood REs to be $16.3 \%{ }^{14}$

Therefore, increased parental awareness regarding the effect of paediatric uncorrected REs is particularly important and could help in prompt diagnosis and management of childhood eye conditions, contributing to a decrease in childhood visual impairment. ${ }^{15}$ No studies have been conducted to date to assess parents' awareness of and perspectives on childhood REs and spectacle wear in Saudi Arabia. Thus, the current study focused specifically on the knowledge and feelings of parents towards childhood RE and spectacle wear because their awareness and beliefs are critical for the success of interventions aimed at reducing childhood visual impairment resulting from uncorrected REs.

\section{Methods}

This was a cross-sectional study and included randomly selected parents aged between 21 and 55 years who had children enrolled in public schools in different regions of Saudi Arabia (central, western, eastern, northern and southern regions). The study was conducted between October and November 2020 and included two schools from each region-one for boys and the other for girls. Data were collected through an online self-administered questionnaire based on a validated questionnaire by Alrasheed et al. and included questions to assess parents' knowledge and perceptions regarding childhood RE and spectacle wear. $^{7,8}$ The questionnaire was distributed by the selected schools through the parents' social media groups and was administered in Arabic.

The inclusion criteria for the study were parents who had children and agreed to participate in the study by signing the consent form. The study sample was calculated using the following formula:

$$
\mathrm{N}=\frac{\left(\mathrm{Z}^{\wedge} 2 \times(P) \times(1-P)\right)}{\mathrm{E}^{\wedge} 2} \quad[\text { Equation } 1]
$$

where $\mathrm{Z}=1.96$ at a confidence level of $95 \%, P=$ outcome of the response, assumed to be $50 \%$ for the parents' awareness of and perspectives on childhood $\mathrm{RE}$ and spectacle wear for the maximum sample size and $\mathrm{E}=$ maximum acceptable sampling error $=5 \%$ or 0.05, in decimal notation. Accordingly, the resulting value was 384 . Considering a $10 \%$ non-participation rate for the calculated sample size, the final sample size for this study was estimated as 422 parents.
Data were collected using a validated questionnaire in Arabic, which was modified based on the literature review and previously published studies. ${ }^{7,8}$ The questionnaire was checked and evaluated by eye care professionals (optometrists and ophthalmologists) and tested with a pilot study of 40 parents. The questionnaire was structured as follows: The first section included the socio-demographic characteristics of the participants. The second section contained questions to assess parents' awareness of childhood RE. The third section covered parents' beliefs regarding RE and spectacle wear. This section included nine positive and negative statements to assess parents' attitudes and perceptions towards childhood RE and spectacle wear. The fourth section included questions related to the prevention and management of childhood visual impairment due to uncorrected RE. Finally, data were entered into a Microsoft Excel 2016 spreadsheet, following which statistical analysis was performed by using the Statistical Package for the Social Sciences (SPSS), Version 22.0 (IBM Corp., Armonk, New York, USA). Before conducting the analysis, the data were tested for entry mistakes and any lost values. Descriptive analyses were used, including the frequencies, proportions, means and standard deviations of the data and $P$ values of $<0.05$ were considered statistically significant.

Ethical approval for the study was obtained from the Biomedical Ethics Committee at Qassim University (\#20-7-03). The study was conducted based on the guidelines of the Declaration of Helsinki. Participation was voluntary and the participants were free to withdraw from the study at any time without citing any reason.

\section{Results}

A total of 422 parents from five different regions of Saudi Arabia were invited to participate in the study. Of the 365 questionnaires that were returned, seven incomplete questionnaires were excluded; thus, 358 completed questionnaires were included in this study (response rate: $85 \%$ ). The study comprised 200 (55.9\%) females and 158 (44.1\%) males and the mean age of the respondents was $36.9 \pm 11.9$ years. A total of $32.7 \%$ of parents fell within the $21-30$ age group and $31.6 \%$ within the $31-40$ age group, while only $13.9 \%$ of participants were more than 50 years of age. Regarding the educational levels of the parents, $70.4 \%$ had a university degree or higher, $22.1 \%$ had secondary certification and only $7.5 \%$ had primary education as their highest qualification [Table 1]. 
Table 1: Demographic characteristics of the parents who participated in this study $(\mathrm{N}=358)$

$\begin{array}{lc}\text { Characteristics } & \mathbf{n}(\%) \\ \text { Gender } & \\ \text { Male } & 158(44.1) \\ \text { Female } & 200(55.9) \\ \text { Age in years } & \\ \text { mean } & 36.9 \pm 11.9 \\ 21-30 & 117(32.7) \\ 31-40 & 113(31.6) \\ 41-50 & 78(21.8) \\ >50 & 50(13.9) \\ \text { Education level } & \\ \text { Primary school } & 27(7.5) \\ \text { Secondary school } & 79(22.1) \\ \text { University degree or higher } & 252(70.4)\end{array}$

Table 2: Parents' knowledge of refractive errors $(\mathrm{N}=358)$

\begin{tabular}{|c|c|c|}
\hline Question & Response & n (\%) \\
\hline \multirow{3}{*}{$\begin{array}{l}\text { Have you ever heard of } \\
\text { refractive errors? }\end{array}$} & No & $137(38.3)$ \\
\hline & I do not know & 45 (12.6) \\
\hline & Yes & $176(49.2)$ \\
\hline \multirow{3}{*}{$\begin{array}{l}\text { Do you think that } \\
\text { refractive errors cause } \\
\text { vision loss for children if } \\
\text { they are untreated? }\end{array}$} & No & $121(33.8)$ \\
\hline & I do not know & $38(10.6)$ \\
\hline & Yes & 199 (55.6) \\
\hline \multirow{3}{*}{$\begin{array}{l}\text { Do you think that } \\
\text { wearing spectacles is } \\
\text { effective in the treatment } \\
\text { of refractive errors in } \\
\text { children? }\end{array}$} & No & $75(21.0)$ \\
\hline & I do not know & $18(5.0)$ \\
\hline & Yes & $265(74.0)$ \\
\hline \multirow{3}{*}{$\begin{array}{l}\text { Have you obtained any } \\
\text { information related to } \\
\text { child eye health? }\end{array}$} & No & $228(63.7)$ \\
\hline & I do not know & $11(3.1)$ \\
\hline & Yes & 119 (33.2) \\
\hline \multirow{3}{*}{$\begin{array}{l}\text { Have you ever taken } \\
\text { your child for an eye } \\
\text { examination? }\end{array}$} & No & 149 (41.6) \\
\hline & I do not know & $15(4.2)$ \\
\hline & Yes & $194(54.2)$ \\
\hline \multirow{3}{*}{$\begin{array}{l}\text { What does your child } \\
\text { use for the treatment of } \\
\text { refractive errors? }\end{array}$} & Glasses & $100(27.9)$ \\
\hline & Contact lens & $4(1.1)$ \\
\hline & None & 254 (70.9) \\
\hline
\end{tabular}

A section of the questionnaire addressed parents' awareness of childhood REs. Approximately half (49.2\%) the parents said that they knew about REs, while $38.3 \%$ reported that they had never heard of REs. The parents were asked whether they thought
Table 3: Comparison of the mean knowledge score of the parents in terms of their age and education level using one-way analysis of variance

\begin{tabular}{lccc} 
Characteristics & & Mean \pm SD & P value \\
Gender & Male & $2.0886 \pm 0.49119$ & \\
\multirow{4}{*}{ Age } & Female & $2.2240 \pm 0.45834$ & 0.008 \\
& $<20$ & $2.2833 \pm 0.51493$ & \\
& $21-30$ & $2.0850 \pm 0.51948$ & \\
& $31-40$ & $2.1709 \pm 0.49425$ & 0.024 \\
Education & $41-50$ & $2.3000 \pm 0.43019$ & \\
level & $>50$ & $2.0894 \pm 0.33312$ & \\
& $\begin{array}{c}\text { Primary } \\
\text { school }\end{array}$ & $1.8545 \pm 0.55062$ & \\
& $\begin{array}{c}\text { Secondary } \\
\text { school }\end{array}$ & $2.1846 \pm 0.45672$ & \\
& $\begin{array}{c}\text { University } \\
\text { degree or } \\
\text { higher }\end{array}$ & $2.1992 \pm 0.45994$ & \\
SD standard deviation. & & \\
& & &
\end{tabular}

that REs caused vision loss in children if left untreated. Among the respondents, $55.6 \%$ mentioned that uncorrected REs led to visual impairment, while 33.8\% of parents responded in the negative. Concerning the effectiveness of using spectacles in the management of REs, the vast majority of the parents (74.0\%) cited using eyeglasses as a good way to manage childhood REs, while $21 \%$ of the respondents reported that wearing spectacles was not good for managing childhood REs. Concerning information related to childhood eye care, $63.7 \%$ of the parents stated that they did not receive any information, while $33.2 \%$ of parents reported having received some information about childhood eye care.

The participants were asked whether they had taken their children for an eye examination. Approximately $54.2 \%$ of respondents cited that they had taken their children for an eye examination, while $41.6 \%$ reported in the negative. Regarding whether their children were using any method of correcting REs, the majority (70.9\%) of parents stated that their children did not use any type of correction, while 27.9\% mentioned that their children used glasses and only $1.1 \%$ reported that their children used contact lenses [Table 2].

Finally, a score was calculated for all the questions assessing the level of parental awareness towards childhood REs. The minimum score was set as 1 for the 'No' response, 2 for 'I do not know the response' and 3 for the 'Yes' response. The average total score was then compared in terms of different demographic variables (gender, age and educational level) using one-way 
Table 4: Parents' attitudes and perceptions towards refractive error and spectacle wear $(\mathrm{N}=358)$

\begin{tabular}{|c|c|c|c|c|c|c|c|}
\hline \multirow[t]{2}{*}{ Statement } & \multicolumn{2}{|c|}{ Total } & \multicolumn{2}{|c|}{ Male } & \multicolumn{2}{|c|}{ Female } & \multirow[t]{2}{*}{$P$ value } \\
\hline & $\begin{array}{l}\text { Disagree } \\
\text { in } \%\end{array}$ & $\begin{array}{l}\text { Agree } \\
\text { in } \%\end{array}$ & $\begin{array}{l}\text { Disagree } \\
\text { in } \%\end{array}$ & $\begin{array}{l}\text { Agree } \\
\text { in } \%\end{array}$ & $\begin{array}{l}\text { Disagree } \\
\text { in } \%\end{array}$ & $\begin{array}{l}\text { Agree } \\
\text { in } \%\end{array}$ & \\
\hline $\begin{array}{l}\text { I think wearing spectacles affects my } \\
\text { child's opportunities for learning. }\end{array}$ & 79.3 & 13.7 & 32.7 & 6.2 & 46.6 & 7.5 & 0.539 \\
\hline $\begin{array}{l}\text { I think wearing spectacles could affect } \\
\text { my child's chances of employment. }\end{array}$ & 82.7 & 14.8 & 34.4 & 7.8 & 48.3 & 7 & 0.048 \\
\hline $\begin{array}{l}\text { I think using spectacles may affect my } \\
\text { child's future marriage prospects. }\end{array}$ & 86.6 & 11.5 & 36.6 & 5.6 & 50 & 5.9 & 0.229 \\
\hline $\begin{array}{l}\text { I believe spectacles could reduce my } \\
\text { child's vision. }\end{array}$ & 70.1 & 22.1 & 26 & 11.7 & 44.3 & 10.4 & 0.005 \\
\hline $\begin{array}{l}\text { I believe using spectacles has a } \\
\text { psychological effect on children. }\end{array}$ & 49.7 & 45.0 & 20.4 & 20.7 & 29.3 & 24.3 & 0.224 \\
\hline $\begin{array}{l}\text { In my opinion, using spectacles could } \\
\text { reduce children's participation in } \\
\text { activities such as sports. }\end{array}$ & 52.8 & 39.7 & 21.2 & 19.3 & 31.6 & 20.4 & 0.061 \\
\hline $\begin{array}{l}\text { I think the best way to prevent vision } \\
\text { loss in my children is having them wear } \\
\text { spectacles. }\end{array}$ & 24.0 & 65.6 & 12.8 & 25.4 & 11.2 & 42.2 & 0.058 \\
\hline $\begin{array}{l}\text { In my opinion, wearing spectacles for } \\
\text { a long time will harm the eyes and may } \\
\text { result in early blindness. }\end{array}$ & 65.9 & 24.3 & 28.2 & 12.3 & 37.7 & 12.1 & 0.008 \\
\hline $\begin{array}{l}\text { In my opinion, spectacles may be used to } \\
\text { relieve distress such as frontal headache, } \\
\text { photophobia and tearing. }\end{array}$ & 59.5 & 27.9 & 25.4 & 12.6 & 34.1 & 15.4 & 0.563 \\
\hline
\end{tabular}

analysis of variance. The results revealed that female parents had a higher mean score $(2.22 \pm 0.46)$, which was statistically significant $(P=0.008)$. The $41-50$ age group had a higher mean score for knowledge (2.30 $\pm 0.43)$, which was statistically significant $(P=0.024)$. Parents with high educational levels had a higher score for awareness $(2.1 \pm 0.45 ; P<0.0001)$ [Table 3 ]

The parents gave a mix of positive and negative answers to the questions concerning their perspectives on childhood REs and the use of eyeglasses. To aid in the assessment of parental attitudes and perceptions, a three-point Likert scale was used in this section, with choices ranging from 'disagree' to 'agree' [Table 4].

Most parents (79.3\%) felt that using eyeglasses did not affect their children's chances of learning, while $13.7 \%$ of parents felt that using eyeglasses could affect their children's chances of learning. However, the difference in the attitudes of the parents was not statistically significant $(P=0.539)$. The vast majority $(82.7 \%)$ of parents thought that wearing spectacles did not reduce their children's employment opportunities, while $14.7 \%$ of participants thought that using eyeglasses could decrease their children's opportunities to find work. The difference in the attitudes of the parents was statistically significant $(P$ $=0.048)$ in this case. Most parents $(86.6 \%)$ supposed that using eyeglasses would not affect their children's marriage prospects in the future. Interestingly, only
$11.5 \%$ of parents believed that using eyeglasses could reduce their children's marriage prospects in the future. In response to the question regarding the use of eyeglasses for the management of RE, $22.1 \%$ of parents noted that wearing eyeglasses would reduce their children's vision. Nevertheless, 70.1\% of parents believed that wearing eyeglasses would not deteriorate their children's vision, which showed statistical significance $(P=0.005)$.

Regarding the question on the psychological effect of wearing spectacles, $45.0 \%$ of parents thought that wearing eyeglasses had a psychological effect on their children, while $49.7 \%$ responded in the negative. The difference in the perceptions of the parents was not statistically significant $(P=0.224)$. Over one third $(39.7 \%)$ of the parents believed that wearing eyeglasses could decrease their children's participation in activities such as sports, while half of the parents thought that wearing eyeglasses did not affect their children's participation in activities. Over half (65.6\%) the parents agreed that wearing eyeglasses prevented their children from developing visual impairment; in contrast, $24.0 \%$ disagreed with this statement. When asked about the effect of wearing glasses for a long time, $65.9 \%$ of participants stated that wearing eyeglasses for a long time did not harm their children's vision, while $24.3 \%$ of parents remarked that using spectacles for a long time would harm their child's 


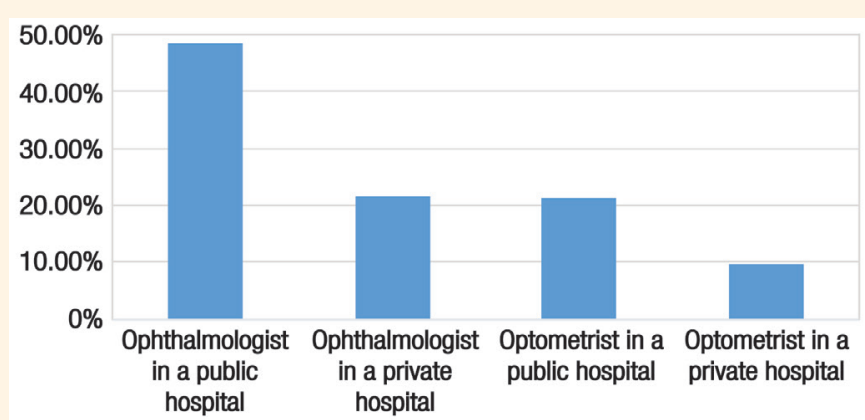

Figure 1: Treatment options sought by parents if their child exhibited symptoms of refractive error $(\mathrm{N}=358)$.

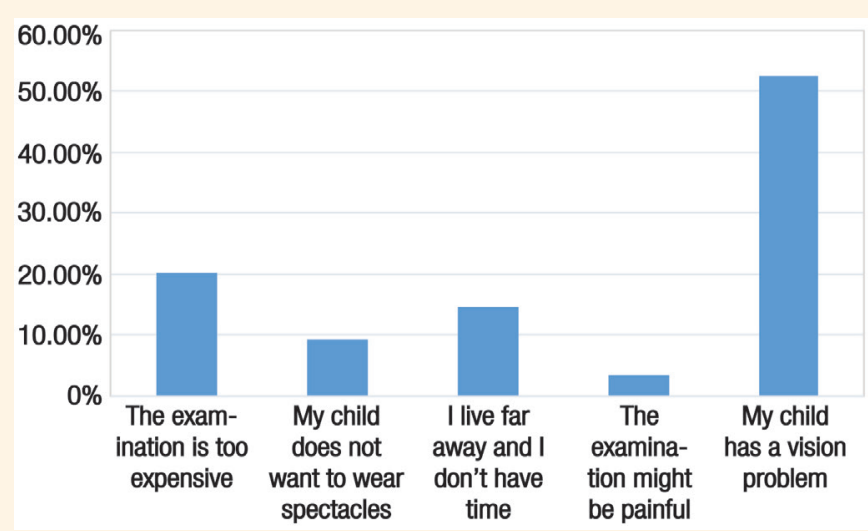

Figure 2: Reasons why parents did not visit an eye care professional for their children $(\mathrm{N}=358)$.

eyes and result in early childhood blindness. The difference in the parents' perceptions was statistically significant $(P=0.008)$ in this case. Most parents (59.5\%) disagreed with the statement that wearing eyeglasses could relieve distress experienced by their children, including frontal headache, while $27.9 \%$ of respondents agreed that wearing eyeglasses would reduce eye discomfort.

The parents were asked about whom they would approach to seek treatment for their children if they complained of symptoms of decreasing vision. A total of $48.3 \%$ of parents stated eye doctors (ophthalmologists) in a public hospital, $21.5 \%$ stated ophthalmologists in a private clinic, $21.2 \%$ stated optometrists in a public hospital and $8.9 \%$ stated optometrists in a private clinic [Figure 1].

The parents were asked about when their children's vision was last examined. Almost half (40\%) the respondents reported that they had not had their children's vision tested before and $35.8 \%$ stated that their children's vision was examined one year prior. The parents were asked to give reasons for not taking their children to eye care professionals in the past 12 months. Half (52.5\%) the parents reported that their child had vision difficulties, 21.1\% reported that the vision examination was too expensive and $14 \%$ reported that hospitals for the vision examination were located far away [Figure 2].

\section{Discussion}

Childhood visual impairment due to uncorrected REs can be avoided through preventive methods and with periodic vision examinations and preliminary treatment. In developed countries, teenagers are required to undergo an eye test at birth, followed by another at six months. ${ }^{16,17}$ After six months of age, an average child has reached numerous developmental milestones in their visual functions and can therefore undergo full vision function examinations. A complete eye examination, including visual functions and binocular vision, is essential at preschool age and frequently during school age. ${ }^{16}$ Parents' awareness of childhood RE and related complaints may encourage them to pursue vision care for their children in a timely manner, which could lead to prompt diagnosis and treatment of eye disorders and help reduce the causes of avoidable childhood blindness. Therefore, the current study aimed to assess parents' awareness of and perspectives on childhood RE and the use of eyeglasses in Saudi Arabia.

In the current study, $38.3 \%$ of parents stated that they did not know the term 'childhood RE.' This figure is lower compared to the findings of Sukati et al., who stated that $53.1 \%$ of parents did not know the term 'childhood RE.'18 Eye health education programmes are needed to increase parents' awareness and to 
correct their misunderstandings regarding childhood REs. Furthermore, $33.8 \%$ of parents thought that uncorrected REs could not cause childhood visual impairment. This result is similar to the findings of a study in India, where $66.7 \%$ of respondents accepted the use of spectacles. However, a considerable number of participants (30.5\%) supposed that the use of spectacles was not an effective method for managing childhood RE. ${ }^{19}$ Therefore, educational interventions to increase parental knowledge of the treatment and prevention of childhood visual impairment due to uncorrected REs are important. In this study, almost $63.7 \%$ of parents indicated that they had not obtained any information related to childhood eye care. This result is higher than that reported among Sudanese parents, where almost $25 \%$ of parents stated that they had not obtained information regarding childhood eye care. ${ }^{8}$ The current study revealed that females had significantly better knowledge than males $(P=$ $0.008)$. The $41-50$ age group had a significantly higher mean knowledge score than the other age groups $(P$ $=0.024)$. Furthermore, knowledge of childhood RE was associated with the parents' educational level $(P$ $<0.001)$. Several authors have reported an association between specific demographic characteristics (i.e. age, gender and level of education) of the parents and knowledge of childhood eye care. ${ }^{16,20,21}$ Aldebasi reported that individuals with advanced educational levels showed more knowledge of RE than those with elementary educational levels. ${ }^{22}$

In this study, a considerable proportion of parents supposed that wearing eyeglasses may affect their children's chances pertaining to learning and employment. This result is similar to those of Alrasheed et al., who reported that parents worried that their children may develop vision impairment and have a dim future if they used eyeglasses. ${ }^{7}$ Almost a quarter (22.1\%) of the parents in the present study thought that using glasses would reduce the eyes' vision, which is consistent with the results of studies conducted in Sudan and Nigeria, where $36.4 \%$ and $23.8 \%$ of parents, respectively, stated that spectacles would harm children's vision. ${ }^{7,23}$ In a survey conducted in southern California, most of the participants experienced distress, sadness and anxiety when they realised that their children needed eyeglasses to improve vision at an early age. ${ }^{24}$ Many parents expressed doubts in the present study, remarking that if their children were advised to use eyeglasses, they would feel as if their children had lost their vision and that it would affect their participation in activities in addition to having an adverse psychological effect. Therefore, childhood eye care education should be delivered through public media, radio, television, social media and newspapers to increase the community's knowledge of and perspectives on childhood eye diseases and to help them understand the importance of early diagnosis and treatment of RE.

The present study has some limitations. It was cross-sectional and was conducted online; therefore, the collected information was sometimes incomplete. To reduce bias, incomplete questionnaires were excluded from the study. Additionally, the participant response rate was slightly low, which may affect the generalisability of the results. The aforementioned limitations notwithstanding, the current study provides insights that could help health policymakers and eye care professionals develop a childhood eye care education plan to improve parents' awareness of childhood eye care.

\section{Conclusion}

The level of awareness regarding childhood REs among parents in Saudi Arabia is low and they have poor perceptions of eyeglasses as a method of RE management. The findings of this study show that there is a need to increase the community's knowledge of RE and disprove related myths and misunderstandings by highlighting the importance of prompt detection and treatment of childhood RE. Therefore, structured educational programmes through mass media are necessary to increase knowledge regarding the effect of childhood RE and visual impairment and corresponding treatment modalities. This study recommends the need to devise a policy to improve the knowledge, attitudes and practices of key stakeholders such as parents and teachers. In turn, such an improvement could play a crucial role in addressing the poor knowledge and perceptions regarding the treatment of childhood RE and spectacle use in Saudi Arabia.

\section{AUTHORS' CONTRIBUTION}

SA and WA designed the study. SA analysed and interpreted the results. WA drafted the manuscript. Both authors discussed the results, commented on the manuscript and approved the final version of the manuscript.

\section{ACKNOWLEDGEMENTS}

The researchers would like to thank the Deanship of Scientific Research, Qassim University, for supporting this project.

\section{CONFLICTS OF INTEREST}

The authors declare no conflicts of interest. 


\section{FUNDING}

No funding was received for this study.

\section{References}

1. Pascolini D, Mariotti SP. Global estimates of visual impairment: 2010. Br J Ophthalmol 2012; 96:614-8. https://doi.org/10.1136/ bjophthalmol-2011-300539.

2. Solebo AL, Rahi J. Epidemiology, aetiology, and management of visual impairment in children. Arch Dis Child 2014; 99:375-9. https://doi.org/10.1136/ arch dis child-2012-303002.

3. Alrasheed SH, Naidoo KS, Clarke-Farr PC. Prevalence of visual impairment and refractive error in school-aged children in the South Darfur State of Sudan. Afr Vision Eye Health 2016; 75:1-9. https://doi.org/10.4102/aveh.v75i1.355.

4. Naidoo KS, Wallace DB, Holden BA, Minto H, Faal HB, Dube P. The challenge of uncorrected refractive error: Driving the agenda of the Durban Declaration on refractive error and service development. Clin Exp Optom 2010; 93:131-6. https://doi.org/10.1111/ j.1444-0938.2010.00455.x.

5. Bourne RR, Flaxman SR, Braithwaite T, Cicinelli MV, Das A, Jonas JB, et al. Magnitude, temporal trends, and projections of the global prevalence of blindness and distance and near vision impairment: A systematic review and meta-analysis. Lancet Glob Health 2017; 5:888-97. https://doi.org/10.1016/S2214109X(17)30293-0.

6. Flaxman SR, Bourne RR, Resnikoff S, Ackland P, Braithwaite T, Cicinelli MV, et al. Global causes of blindness and distance vision impairment 1990-2020: A systematic review and metaanalysis. Lancet Glob Health 2017; 5:1221-34. https://doi. org/10.1016/S2214-109X (17)30393-5

7. Alrasheed SH, Naidoo KS, Clarke-Farr PC. Attitudes and perceptions of Sudanese high-school students and their parents towards spectacle wear. Afr Vision Eye Health 2018; 77:1-7. https://doi.org/10.4102/aveh.v77i1.392.

8. Alrasheed SH, Naidoo KS, Clarke-Farr PC. Childhood eye care services in the South Darfur State of Sudan: Learner and parent perspectives. Afr Vision Eye Health 2016; 75:1-9. https://doi. org/10.4102/aveh.v75i1.315.

9. Abdi Ahmed Z, Alrasheed SH, Alghamdi W. Prevalence of refractive error and visual impairment among school-age children of Hargeisa, Somaliland, Somalia. East Mediterr Health J 2020; 26:1362-70. https://doi.org/10.26719/emhj.20.077.

10. Yu L, Li Z-K, Gao J-R, Liu J-R, Xu C-T. Epidemiology, genetics, and treatments for myopia. Int J Ophthalmol 2011; 4:658-69. https://doi.org/10.3980/j. ISSN.2222-3959.2011.06.17.

11. World Health Organization. Global Initiative for the Elimination of Avoidable Blindness: Action Plan 2006-2011. Geneva, Switzerland: WHO. From: https://apps.who.int/iris/handle/1066 5/43754 Accessed: Sept 2021.
12. Alrasheed SH, Naidoo KS, Clarke-Farr PC, Binnawi KH. Building consensus for the development of child eye care services in South Darfur State in Sudan using the Delphi technique. Afr J Prm Health Care Med 2018; 10:1-9. https://doi.org/10.4102/ phcfm.v10i1.1767.

13. Al Wadaani FA, Amin TT, Ali A, Khan AR. Prevalence and pattern of refractive errors among primary school children in Al Hassa, Saudi Arabia. Glob J Health Sci 2012; 5:125-34. https://doi.org/10.5539/gjhs.v5n1p125.

14. Aldebasi $\mathrm{YH}$. Prevalence of amblyopia in primary school children in Qassim province, Kingdom of Saudi Arabia. Middle East Afr J Ophthalmol 2015; 22:86-91. https://doi.org/10.4103/09749233.148355.

15. Al-Rasheed SH, Elmadina AEM. The effect of binocular vision problems on childhood academic performance and teachers' perspectives. Pak J Ophthalmol 2020; 36:162-7. https://doi. org/ 10.36351/pjo.v36i2.896.

16. Baashar AS, Yaseen AA, Halawani MA, Alharbi WI, Alhazmi GA, Alam SS, et al. Parents' knowledge and practices about child eye health care in Saudi Arabia. Int J Med Dev Ctries 2020; 4:454-60. https://doi.org/10.24911/IJMDC.51-1577288335.

17. Alrasheed SH, Naidoo KS, Clarke-Farr PC, Binnawi KH. Building consensus for the development of child eye care services in South Darfur State in Sudan using the Delphi technique. Afr J Prm Health Care Med 2018; 10:1-9. https://doi.org/10.4102/ phcfm.v10i1.1767.

18. Sukati VN, Moodley VR, Mashige KP. Knowledge and practices of parents about child eye health care in the public sector in Swaziland. Afr J Prm Health Care Fam Med 2018; 10:1-13. https://doi.org/10.4102/phcfm.v10i1.1808.

19. Chawla K, Rovers J. Survey of patient opinions on eyeglasses and eye care in rural and slum populations in Chennai. Int J Epidemiol 2009; 8:1-5.

20. Amiebenomo OM, Achugwo DC, Abah I. Parental knowledge and attitude to children's eye care services. Niger J Paediatr 2016; 43:215-20. https://doi.org/10.4314/njp.v43i3.11.

21. Ormsby GM, Arnold AL, Busija L, Mörchen M, Bonn TS, Keeffe JE. The impact of knowledge and attitudes on access to eye-care services in Cambodia. Asia Pac J Ophthalmol (Phila) 2012; 1:331-5. https://doi.org/10.1097/APO.0b013e31826d9e06.

22. Aldebasi Y. Young public's awareness to refractive error deficiency. Int J Health Sci (Qassim) 2011; 5:9-15

23. Ayanniyi AA, Olatunji FO, Mahmoud AO, Ayanniyi RO. Knowledge, and attitude of guardians towards eye health of primary school pupils in Ilorin, Nigeria. Niger Postgrad Med J 2010; 17:1-5.

24. Kodjebacheva GD, Maliski S, Coleman AL. Use of eyeglasses among children in elementary school: Perceptions, behaviors, and interventions discussed by parents, school nurses, and teachers during focus groups. Am J Health Promot 2015; 29:324-31. https://doi.org/10.4278/ajhp.120315-QUAL-140. 